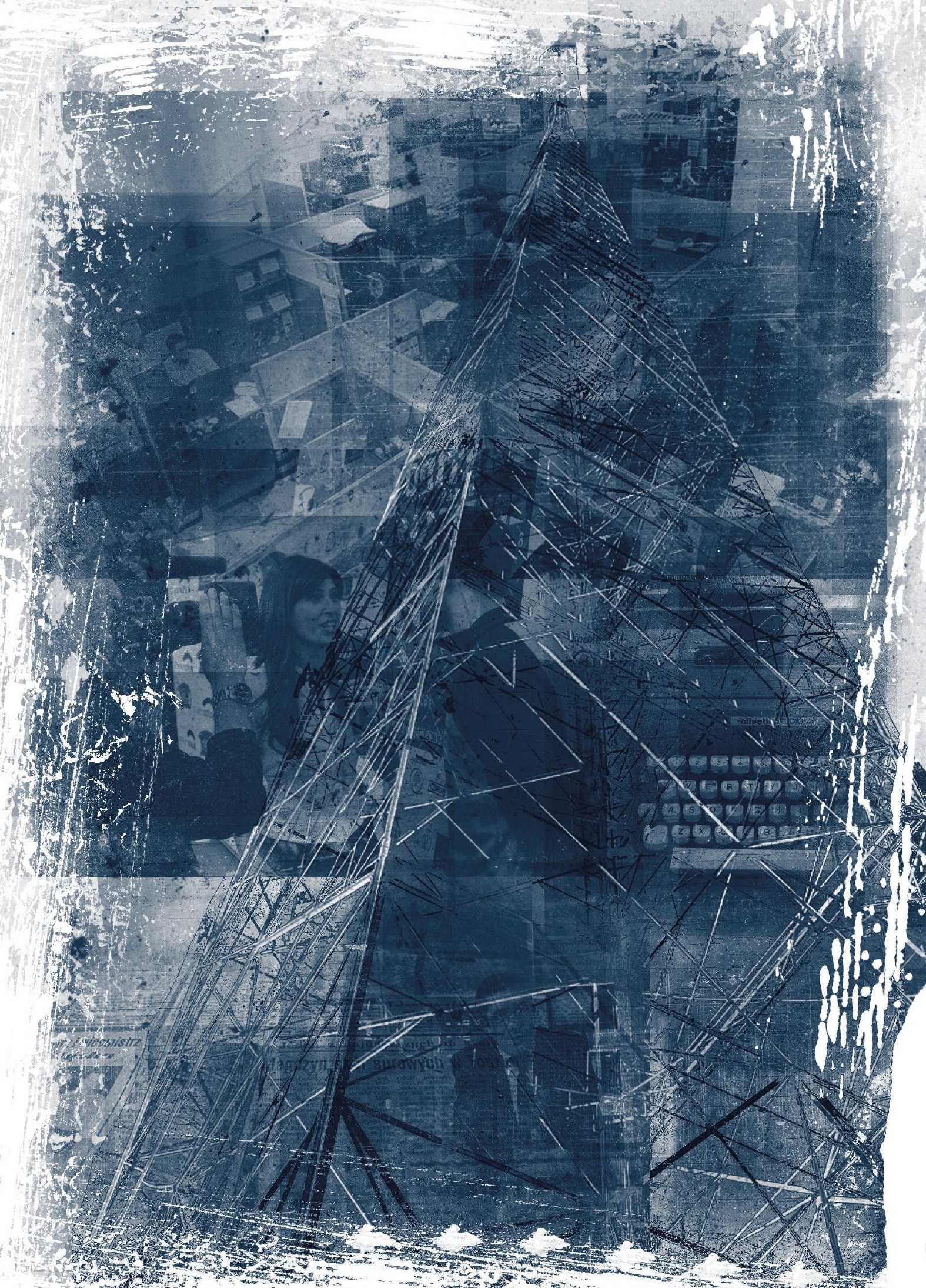




\section{PERIODISMO DE INMERSIÓN}

\section{López Hidalgo, Antonio y Fernández Barrero, María Ángeles (2014) Ed.: Comunicación Social Ediciones y Publicaciones Salamanca, 192 páginas}

DoI: 10.15213/redes.n10.p389

FRANCISCO SIERRA CABALLERO

Que el oficio y la función periodística están en crisis es hoy un lugar común en la academia y el campo profesional. La creciente precariedad y el intrusismo, los excesos y abusos del "periodismo de gabinete", la esclerosis múltiple de las estériles rutinas productivas, las patologías de la información (sensacionalismo, espectacularidad, mercantilismo, descontextualización, saturación inflacionaria), junto a la creciente dependencia del capital financiero, sitúan el periodismo en una compleja encrucijada que, paradójicamente, ha hecho posible la emergencia de nuevas formas creativas de producción del relato del acontecer social. Periodismo de inmersión parte de este diagnóstico de cuestionamiento de la función productiva de la información de actualidad para explicar la proliferación de modalidades si bien ciertamente nada originales sí cuando menos rupturistas, y quizás por lo mismo marginales en los medios. La hipótesis de partida pues del libro es lo que algunos denominamos principio wikileaks. Los medios encubiertos, de inmersión, expresan la condición, la opción narrativa inexcusable, para el acceso y tratamiento contemporáneo de la información sustantiva en nuestras democracias. Esto es, en la era hipermediatizada de la convergencia digital, Antonio López y María Ángeles Fernández demuestran:

1. Que otro concepto y praxis del periodismo es posible. Desde el periodismo muckraking al periodismo gonzo y al periodismo narrativo latinoamericano, la realidad puede ser contada de manera no convencional ni rutinaria, más allá de los tópicos, declaraciones y fuentes sobrerrepresentadas de la información convencional.

2. Que emerge en nuestra región cultural una nueva crónica y exploración, estética y política, original liderada por el 
periodismo narrativo latinoamericano, que debe ser referencia y modelo de expresión privilegiado de la contemporaneidad.

3. Que la cámara oculta y el espectáculo televisivo emergente proliferantes en las televisiones en España permiten hoy reavivar la información periodística audiovisual con nuevos patrones, y también riesgos éticos y legales, propios del periodismo de investigación, que actualizan y dan cuenta de la viveza del oficio y las potencialidades de un modo arriesgado de contar el acontecer social.

4. Que los peligros que acechan al periodismo de investigación, el riesgo de cruzar los límites de los que el profesor López Hidalgo tanto sabe (profesionalmente, como periodista, protagonista de la primicia sobre las luchas del sindicato de la Guardia Civil en la Transición; pero también, académicamente, innovando en la investigación sobre géneros periodísticos, siendo su obra una referencia imprescindible en España y América Latina) apuntan a la emergencia de nuevos procesos contradictorios de lucha y control del derecho a decir, de la libertad de expresión en la línea de exploración de trabajos anteriores sobre la soledad de los informadores y la amenaza de la precariedad laboral.

Se trata pues de una obra y aporte fundamental al explorar un fenómeno prácticamente desatendido por la investigación periodística en España y América Latina, pese a su creciente importancia. En su trabajo de investigación, ambos autores analizan las características esenciales de esta nueva cultura de la información:

1. La reivindicación de la creatividad y la experimentación como principio esencial de la actividad periodística.

2. El retorno al periodismo de denuncia, caso del periodismo muckraking, que reveló la explotación, la corrupción, los abusos del poder, la mala vida de los inmigrantes y las injusticias en la periferia del centro del sistema industrial estadounidense, en la estela pionera de John Reed y el periodismo comprometido de los años veinte y principios de siglo $\mathrm{xx}$, que tanto aportó a través de singulares cronistas como Upton Sinclair, cuya 
reciente edición a cargo de César de Vicente Hernando recomendamos.

3. La dimensión performativa de toda mediación, que actualiza la teoría del montaje de Eisenstein, explorando la teatralidad de las experiencias de denuncia como las de Nellie Bly, en su retrato de la injusticia social en manicomios y cárceles de Estados Unidos.

4. La importancia de la función contrainformativa y de participación activa del periodista en los hechos, como ilustra $\mathrm{H}$. Thompson en el origen del periodismo gonzo.

5. La pasión como actitud y principio rector de la actividad periodística frente al periodismo de declaraciones, pese a que, como demuestra la propia noción de periodismo gonzo, esta actitud irreverente ha sido objeto de numerosas críticas de los defensores del modelo angloamericano de profesión, llegando a ser incluso el concepto 'gonzo' un término peyorativo para descalificar las formas experimentales de producción periodística.

6. El carácter metadiscursivo, que cuestiona, impugna, piensa el propio discurso periodístico, fomentando la reflexividad sobre la propia práctica del periodismo, tal y como se evidencia en el nuevo periodismo narrativo latinoamericano.

7. La elaboración artesanal, cuidadosa de los textos, siendo una modalidad de información con tiempo distendido. Pues si, como advertía Abraham Moles, el tiempo es el único capital no reproducible, ni acumulable que dispone el ser humano, el 'periodismo de inmersión' es, en cierto modo, un periodismo basado en el elogio de la lentitud, en el deleite y cultivo reposado del arte de narrar, o como recomendara Kapuscinski, un tipo de tratamiento informativo inspirado en el saber ver, escuchar, vivir y sentir, presente en los hechos.

Quienes se oponen al periodismo de investigación argumentan que el fin no justifica siempre los medios, y con este razonamiento se defiende que el 
periodista siempre debe identificarse, ya que el encubrimiento es, o debería ser, un método de investigación exclusivamente reservado para policías

y agentes secretos, no para periodistas, cuando en realidad lo que se está negando es la dimensión proyectiva de la información de actualidad, una divisa que ha sido una constante del periodismo de calidad, tal y como documentan en su estudio los autores. Mucho antes, como bien se detalla en el libro, que el llamado Nuevo Periodismo estadounidense, autores como Manuel Chaves Nogales en España, o la prensa satírica y política de finales del xix, innovan en países latinos del Sur de Europa las técnicas narrativas, hibridando géneros, y explorando el factor subjetivo en la aproximación y tratamiento de la realidad. De estas experiencias históricas originales a los trabajos sobre lo real maravilloso de Leila Guerreiro, Lydia Cacho o Solano se puede percibir un fino hilo rojo de la historia del periodismo, tal y como se demuestra en una de las tesis del trabajo cuando se señala la continuidad y necesaria ruptura con la nueva generación de cronistas manifiesta en autores como Juan Villoro o Leila Guerriero, en el paso de lo que algunos autores, como Javier Rodríguez Marcos, resume como el proceso de transición de lo real maravilloso a lo maravilloso real.

Las pasiones, la emoción, las sensaciones y singularidad creativa del quehacer periodístico activan así el patrimonio cultural de la nueva crónica periodística instituyendo como referente un sensorium que desde los años sesenta alteró el modo de narrar y pensar la región por medio de la orfebrería y la apertura cognitiva al mundo real maravilloso y que en España tiene ilustres antecedentes, no suficientemente reconocidos a nivel internacional, como el citado Chaves Nogales.

En esta iluminación reside el valor sobre el que levanta el vuelo la nueva escritura periodística y las enseñanzas que nos ofrecen los autores cuyas tesis se pueden resumir en dos párrafos magistrales del libro:

I.- El tipo de periodismo que hacen Gunter Walraff y Lydia Cacho representa un dilema ético, y está en el origen mismo del periodismo moderno. En el siglo xix, hubo periodistas encubiertos que representaron causas sociales, y después en el desarrollo del siglo xx, sobre todo en el periodismo norteamericano, surgió la idea de la imparcialidad y del periodista como una especie de defensor de este equilibrio entre 
las partes. Pero esa contradicción siempre ha estado presente de algún modo en las matrices o epistemologías de concepción de la dialéctica informativa (López Fernández, 2014: 117).

II.- "Desde Gunter Walraff hasta los actuales profesionales que hoy cultivan la crónica en Latinoamérica, el periodismo de investigación vive al margen de la ley - aunque no fuera - en una tierra de nadie, visible sólo en un espejo que proyecta su propia sombra y que deja ver a las claras esta pátina delgada y a veces invisible que enmascara la realidad".

Los autores de este estudio imprescindible nos muestran y demuestran que solo así tiene sentido leer la realidad e informarla. Como enseñara Brecht, hay que enmascararse para desenmascarar a la sociedad, hay que engañar y fingir para averiguar la verdad, como lo hacen, y bien lo sabe en su oficio, en su buen oficio, la alta literatura y la narrativa y crónica de calidad. 